\title{
Determination of bisphenol A and 4-nonylphenol in media samples for in vitro fertilization by high-performance liquid chromatography with tandem mass spectrometry
} \author{
Tsunehisa Makino ${ }^{5^{*}}$ \\ ${ }^{1}$ Division of Water and Food, Saitama Prefectural Institute of Public Health, Saitama, Japan \\ ${ }^{2}$ Division of Food Chemistry, Osaka Prefectural Institute of Public Health, Osaka, Japan \\ ${ }^{3}$ Division of Pharmacology, Aichi Medical University, Aichi, Japan \\ ${ }^{4}$ Department of Analytical Chemistry, Hoshi University, Tokyo, Japan \\ ${ }^{5}$ Tobu Hospital, Shizuoka, Japan; ${ }^{*}$ Corresponding Author: tmakino@k4.dion.ne.jp
}

Rie Ishii ${ }^{1}$, Satoshi Takatori ${ }^{2}$, Kazuhiko Akutsu ${ }^{2}$, Fumio Kondo ${ }^{3}$, Hiroyuki Nakazawa ${ }^{4}$,

Received 27 March 2013; revised 28 April 2013; accepted 13 May 2013

Copyright (C) 2013 Rie Ishii et al. This is an open access article distributed under the Creative Commons Attribution License, which permits unrestricted use, distribution, and reproduction in any medium, provided the original work is properly cited.

\begin{abstract}
In vitro fertilization (IVF) is an important treatment for infertility, and in recent years, the delivery rate in IVF has increased markedly with the progress of reproductive medicine. However, chemical contaminants in IVF media have not been fully studied. A simple method using highperformance liquid chromatography coupled with tandem mass spectrometry was therefore investigated for quantitation of bisphenol A (BPA), 4nonylphenol (NP) and 4-n-nonylphenol ( $n$-NP) in IVF media. Media samples were processed using the solid-phase extraction method. The quantitation limits of BPA, NP, and $n$-NP were $0.5,5$ and $0.5 \mathrm{ng} \cdot \mathrm{ml}^{-1}$, respectively, and the recoveries for BPA, NP and $n$-NP added to the media samples were above $90 \%$. Commercially available media samples for IVF including 15 media for incubation of ova, 9 sperm washing media (SWM), 4 human serum albumin (HSA) samples and 2 substitute serum (SS) samples were examined, with 2 lots for each sample. NP was detected in 3 media for incubation of ova, 12 SWM, 7 HSA samples and 4 SS samples, in ranges of $6.3-14.5$,

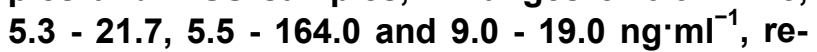
spectively. BPA and $n$-NP were not detected in any of the samples.
\end{abstract}

Keywords: Nonylphenol; Bisphenol A; Media for in Vitro Fertilization; LC-MS/MS; Human Serum

\section{Albumin}

\section{INTRODUCTION}

Humans are potentially exposed to a wide range of chemicals presented in commonly used products. These chemicals include bisphenol A (BPA) and alkylphenols (APs) such as 4-nonylphenol (NP). BPA is a synthetic substance that is widely used in the production of epoxy resins and polycarbonates, and it acts as an antioxidant in polyvinyl chloride plastics. Epoxy resins are used as an inner surface coating in food and beverage cans, while polycarbonates are used in the manufacture of plastic food containers. The migration of BPA from epoxycoated surfaces [1,2], polycarbonate plastics [3] and polyvinyl chloride products [4] into food has been reported. APs are used to make alkylphenol ethoxylates, which are widely used nonionic surfactants. NP is one of the most widely used and studied APs. Some researchers have reported the widespread presence of NP in various products for human consumption [5-7]. Thus, because of the widespread use of BPA and NP, the potential for human exposure is high.

In recent decades, NP and BPA have attracted much attention due to their potential endocrine-disrupting effects and toxicity in wildlife, as well as their effects on human health [8-11]. NP has estrogenic activity in vitro and in vivo, interferes with the estrous cycle and pubertal onset in rats [12], and shows aquatic toxicity at low (micrograms per litter) concentrations [13]. In mice treated with BPA at oral doses comparable with environmental 
exposure levels, BPA appears to be a potent disruptor of meiosis, the cell division process that creates sperm or eggs, leading to aneuploidy [14].

In vitro fertilization (IVF) is an important treatment for infertility [15]. The birth rate in IVF has increased markedly with the progress of reproductive medicine. In IVF treatment, ova are incubated in an appropriate media for IVF (IVFM), and sperm are prepared with sperm washing media (SWM). IVFM and SWM are typically supplemented with a protein source (PS). Both human serum albumin (HSA) and substitute serum (SS) solution are used as PS. IVFM and SWM containing PS are also commercially available. However, the chemical contaminants in these media have not been fully examined. Therefore, there is an urgent need to determine the concentrations of these contaminants in commercial media for IVF, and for a simple, quantitative method for the determination of these substances in IVFM. The aim of this study is to develop a quantitative method for the determination of BPA and NP in media and PS for IVF using LC-MS/MS, and to investigate the concentrations of these chemical substances in the commercial media and PS for IVF in Japan.

\section{MATERIAL AND METHODS}

\subsection{Samples}

The samples used in this study included 15 IVFM, 9 SWM, 4 HSA samples and 2SS samples which were commercially available, with 2 lots for each sample, except for one of the 4 HSA samples. Each sample was given a code name for this study.

\subsection{Materials and Reagents}

BPA standard was purchased from Wako Pure Chemical Co., Ltd. (Osaka, Japan). NP standard, 4-n-nonylphenol-d4 (n-NP-d4) standard, bisphenol A-d16 (BPAd16) standard, acetonitrile, methanol and pure water of high liquid chromatography grade were supplied by Kanto Chemical Industries (Tokyo, Japan). 4-(1-methyl) octylphenol-d5 (NP-d5) was supplied by Hayashi Pure Chemical Co., Ltd. (Osaka, Japan). 4-n-nonylphenol ( $n$ NP) standard was supplied by Dr. Ehrenstorfer GmbH. (Augsburg, Germany). $\beta$-Glucuronidase Type H-2 was purchased from Sigma-Aldrich (St Louis, MO).

Standard stock solutions were prepared by accurately weighing $50 \mathrm{mg}$ of each standard and dissolving them in acetonitrile to a final volume of $50 \mathrm{ml}$, and were prepared to be $0.2-40 \mathrm{ng} \cdot \mathrm{ml}^{-1}$ coexisting with $50 \mathrm{ng} \cdot \mathrm{ml}^{-1}$ internal standard (NP-d5, $n$-NP-d4 and BPA-d16) by addition of acetonitrile-water (1:1). All standard solutions were stored at $4^{\circ} \mathrm{C}$. The solid-phase extraction (SPE) cartridges for pre-treatment of BPA and NP in samples were Isolute multimode SPE $(=\mathrm{C} 18+$ strong cation exchange
+ strong anion exchange function groups) $300 \mathrm{mg}$ cartridges from International Sorbent Technology Ltd. (Tucson, AZ), Sep-pak Vac C18 (200 mg), OASIS HLB (200 $\mathrm{mg}$ ), Sep-pak PS-2 Plus (265 mg) from Waters (Elstree, UK), and Aqusis PLS-3 (200 mg) from GL Science Inc. (Tokyo, Japan).

\subsection{Apparatus and Conditions}

An Alliance 2695 LC system (Waters) was used for chromatography. Detection was performed using a Quattro Premier (Waters) with an electrospray ionization source, and was run using MassLynx 4.1 software. The LC analytical column was a Symmetry C18 $(100 \times 2.1$ $\mathrm{mm}, 3 \mu \mathrm{m}$; Waters). Samples and calibration standards were run on the Quattro Premier in multiple reaction monitoring (MRM) mode using electrospray ionization. LCMS/MS parameters are given in Table 1, and MRM parameters are listed in Table 2.

\subsection{Calibration}

Internal calibration was used for quantitation. Briefly, calibration curves for BPA, NP and $n$-NP were obtained from the peak-area ratio (BPA/BPA-d16) versus BPA concentration, (NP/NP-d5) versus NP concentration, and ( $n$-NP/n-NP-d4) versus $n$-NP concentration, respectively. Quantification was performed using the Waters QuanLynx module of MassLynx software.

\subsection{Sample Preparation}

Each internal standard (250 ng) was added to $5 \mathrm{ml}$ samples of IVFM, SWM, HSA and SS. Before extracting samples, SPE cartridges were conditioned using $5 \mathrm{ml}$ of acetonitrile, followed by $5 \mathrm{ml}$ of water. Samples were passed through the SPE cartridges, and were then washed with $5 \mathrm{ml}$ of water, followed by elution with $2.5 \mathrm{ml}$ of acetonitrile. The elution solution was made up to $5 \mathrm{ml}$ with water, and a $5 \mu \mathrm{l}$ aliquot was injected for LC-MS/MS.

For determination of BPA-, NP- and n-NP-conjugated glucuronate, samples were pre-treated with $\beta$-glucuronidase before extraction with SPE cartridges, in accordance with a modification of the reported method [16]. Briefly, $1 \mathrm{ml}$ of sample was added to an extraction polypropylene tube, and each internal standard solution, 2 $\mathrm{ml}$ of $0.2 \mathrm{M}$ acetic buffer ( $\mathrm{pH} 5.0$ ) and $50 \mu \mathrm{l}$ of $\beta$-glucuronidase $(10,000$ units $/ \mathrm{ml})$ was added. After incubation for $90 \mathrm{~min}$ at $37^{\circ} \mathrm{C}, \mathrm{BPA}, \mathrm{NP}$ and $n$-NP were extracted with SPE cartridges as described above.

\section{RESULTS AND DISCUSSION}

\subsection{Mass Spectrometry Condition}

Mass spectrometer settings were optimized while in- 
Table 1. LC-MS/MS conditions.

\begin{tabular}{|c|c|c|c|c|}
\hline Parameter & \multicolumn{4}{|l|}{ Settings } \\
\hline \multicolumn{5}{|l|}{ LC parameters } \\
\hline \multirow[t]{8}{*}{ Mobile phase } & $\mathrm{A}=$ water & & & \\
\hline & $\mathrm{B}=$ methanol & & & \\
\hline & $\mathrm{C}=10 \mathrm{mM}$ annmonium & & & \\
\hline & Time (min) & A $(\%)$ & B $(\%)$ & $\mathrm{C}(\%)$ \\
\hline & 0 & 35 & 60 & 5 \\
\hline & 5 & 35 & 60 & 5 \\
\hline & 5.5 & 5 & 90 & 5 \\
\hline & 12 & 5 & 90 & 5 \\
\hline Flow rate & $0.2 \mathrm{ml} \cdot \mathrm{ml}^{-1}$ & & & \\
\hline Column temperature & $40^{\circ} \mathrm{C}$ & & & \\
\hline Injection volume & $5 \mu 1$ & & & \\
\hline Run time & $12 \mathrm{~min}$ & & & \\
\hline \multicolumn{5}{|l|}{$\mathrm{AP}$ interface parameters ${ }^{\mathrm{a}}$} \\
\hline Ionization mode & $\begin{array}{l}\text { Electrospray ionization } \\
\text { (negative mode) }\end{array}$ & & & \\
\hline Capillary voltage & $3.2 \mathrm{kV}$ & & & \\
\hline Source temperature & $120^{\circ} \mathrm{C}$ & & & \\
\hline Desolvation temperature & $400^{\circ} \mathrm{C}$ & & & \\
\hline Cone gas flow & $50 \mathrm{~L} / \mathrm{hr}$ & & & \\
\hline Desolvation gas flow & $900 \mathrm{~L} / \mathrm{hr}$ & & & \\
\hline \multicolumn{5}{|l|}{ Analyser parameters } \\
\hline MS1 resolution & 11.0 & & & \\
\hline MS1 ion energy & 0.5 & & & \\
\hline MS2 resolution & 11.0 & & & \\
\hline MS2 ion energy & 1.5 & & & \\
\hline Multiplier & $650 \mathrm{~V}$ & & & \\
\hline
\end{tabular}

Note: ${ }^{\mathrm{a}} \mathrm{AP}=$ Atmospheric pressure.

Table 2. MRM parameters.

\begin{tabular}{|c|c|c|c|c|}
\hline & Monitoried reactions & Dwell & Cone & Collision \\
\hline \multirow[t]{2}{*}{ Analyte $^{\mathrm{a}}$} & Precursor $\mathrm{m} / \mathrm{z}$ & Time & Voltage & Energy \\
\hline & $>$ product $\mathrm{m} / \mathrm{z}$ & (s) & (V) & $(\mathrm{eV})$ \\
\hline \multirow[t]{2}{*}{ BPA } & $227>133$ & 0.2 & 40 & 20 \\
\hline & $227>212^{\mathrm{c}}$ & 0.2 & 40 & 20 \\
\hline BPA-d $16^{\mathrm{b}}$ & $241>223$ & 0.05 & 40 & 20 \\
\hline NP & $219>133$ & 0.2 & 45 & 30 \\
\hline $\mathrm{NP}-\mathrm{d} 5^{\mathrm{b}}$ & $224>123$ & 0.05 & 46 & 30 \\
\hline $\mathrm{n}-\mathrm{NP}$ & $219>106$ & 0.2 & 47 & 20 \\
\hline n-NP-d4b & $223>110$ & 0.05 & 50 & 20 \\
\hline
\end{tabular}

Notes: ${ }^{\mathrm{B} B P}$,bisphenol A; BPA-d16, bisphenol A-d16; NP, 4-nonylphenol; NP-d5, 4-(1-methyl) octyl-phenol-d5; $n$-NP, 4- $n$-nonylphenol; $n$-NP-d4, 4-n-nonylphenol-d4. ${ }^{b}$ Internal standard. ${ }^{\mathrm{c}}$ Underlined product ion is that used for confirmation, others for quantitation. 
fusing analyte standards. In full-scan MS mode, the mass spectra of analytes revealed typically de-protonated molecular ions $[\mathrm{M}-\mathrm{H}]^{-}$as base peaks. The best measurement conditions for capillary voltage, temperature and desolvation gas flow were examined, and these conditions are shown in Table 1. Some sensitive fragment ions given by the precursor ion of BPA in collision-induced dissociation were observed, and the most sensitive ion was set as the quantitation ion and the secondary sensitive ion was set as the confirmation ion. However, precursor ions for NP and $n$-NP gave the only one ion as a fragment ion. Therefore, confirmation ions could not be set for product ions of NP and $n$-NP. Fragment ions, the optimized cone voltage and collision energy are shown in Table 2 . Good sensitivity and a sufficient number of points for the peaks were achieved.

\subsection{Liquid Chromatography Conditions}

In this study, chromatographic conditions were carefully studied in order to find a suitable mobile phase with good resolution for BPA, NP, $n$-NP and endogenous interfering substances in samples. Mobile phases including methanol (or acetonitrile) and water with different eluting programs were investigated. Initially, various proportions of methanol from 40 to $80 \%(\mathrm{v} / \mathrm{v})$ were tested as

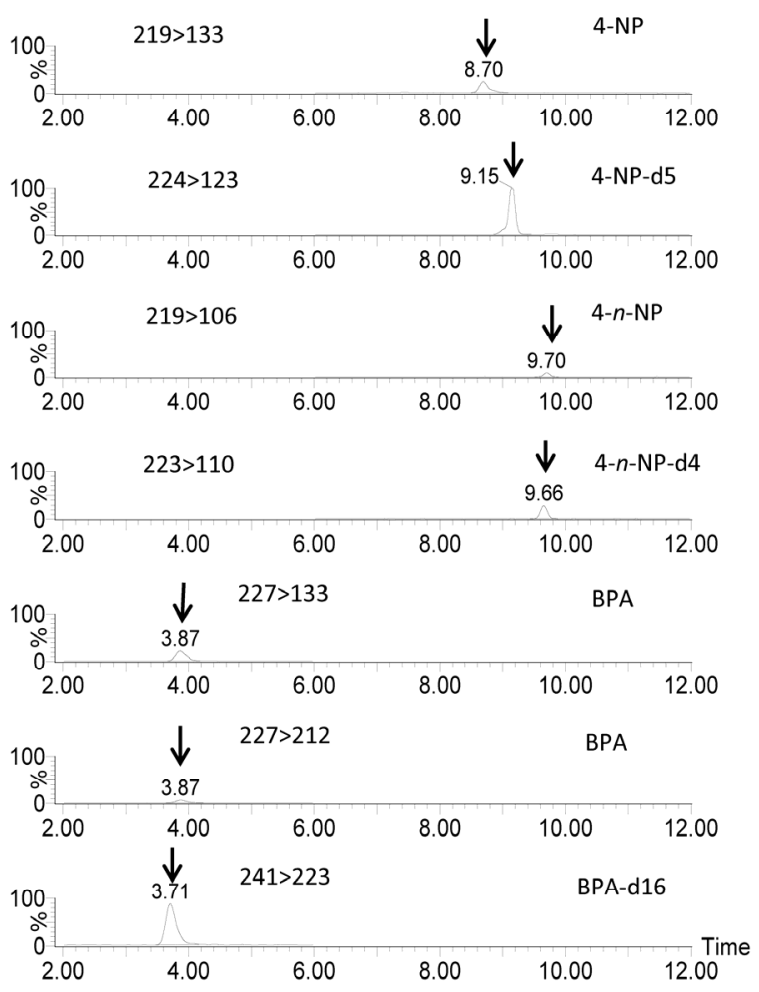

(a) the mobile phase. BPA was eluted with interfering substances at high ratios of methanol (or acetonitrile), and this caused suppression of ionization. The following gradient elution program was selected: methanol: water $(60: 40 \%, \mathrm{v} / \mathrm{v})$ was used within the first $5.0 \mathrm{~min}$, after which the proportion of methanol was rapidly increased from 60 to $90 \%$ in $0.5 \mathrm{~min}$, and maintained for $6.5 \mathrm{~min}$ in order to speed up to the elution of NP and $n$-NP. It was observed in our experiments that replacement of methanol by acetonitrile could result in poor sensitivity.

The acid and salts added to the mobile phase for acceleration and stabilization for ionization were examined. Ammonium acetate was superior to other additives, including ammonium formate, acetic acid and formic acid, with respect to MS sensitivity. The monitored signals for NP showed maximum values with $0.5 \mathrm{mM}$ ammonium acetate. Satisfactory separation of BPA, NP and $n$-NP was achieved within $10 \mathrm{~min}$, with the retention times of 3.7, 8.7 and 9.7 min for BPA, NP and $n$-NP, respectively. Chromatograms are shown in Figure 1(a).

\subsection{Sample Preparation}

Various SPE columns, Sep-pak Vac C18, OASIS HLB, Sep-pak PS-2 Plus, Aqusis PLS-3 and Isolute multimode

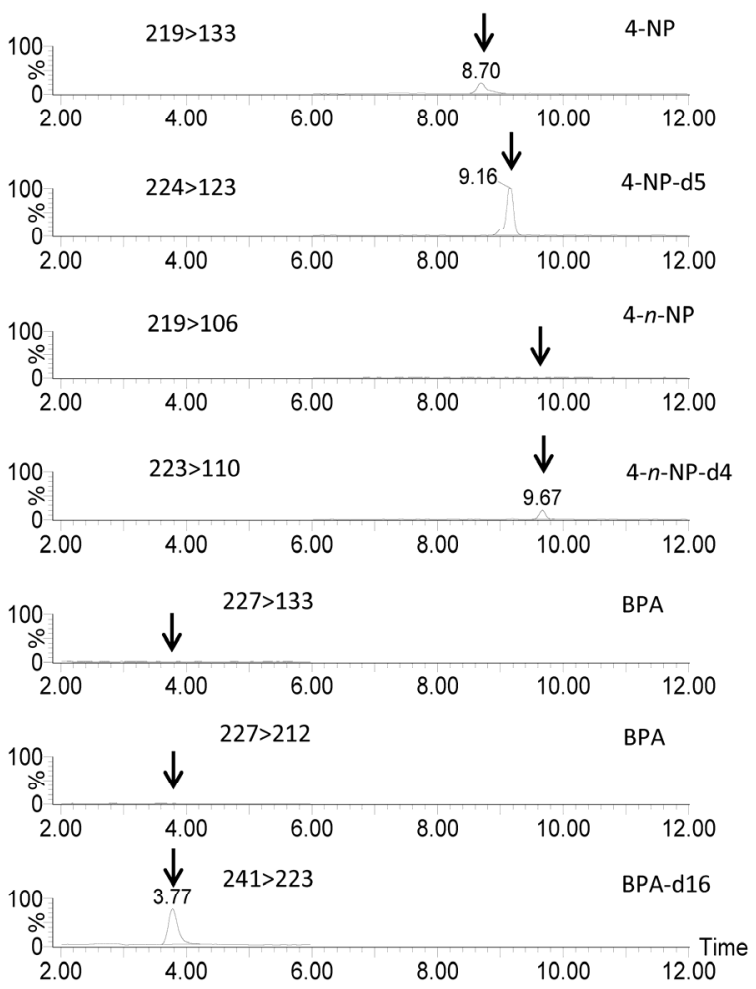

(b)

Figure 1. MRM chromatograms for standard solutions (concentrations of BPA, NP and $n$-NP were $10 \mathrm{ng} \cdot \mathrm{ml}^{-1}$, and concentration of the internal standard was $50 \mathrm{ng} \cdot \mathrm{ml}^{-1}$ ) (a), and a serum substitute sample (A035120, see Table 6) containing $11.7 \mathrm{ng} \cdot \mathrm{ml}^{-1}$ 4-nonylphenol (b). Scales are equal in both chromatograms. 
SPE, were compared for their recovery rates, relative standard deviations and cleanness. Analyte recovery rates were obtained using $5 \mathrm{ml}$ of media spiked with BPA, NP and $n$-NP at concentrations of $50 \mathrm{ng} \cdot \mathrm{ml}^{-1}$. Extraction using SPE cartridges was performed according to the above-described method. Analyte recovery was above $85 \%$ for all SPE cartridges. The Isolute multimode column showed higher recovery and better cleanness for media samples when compared with the other columns. When the elution solvent from SPE cartridges were evaporated to dryness under a nitrogen stream, $84 \%$ of NP and $17 \%$ of $n$-NP were found to be vaporized. Therefore, the evaporation procedure was excluded in this method. Acetonitrile was superior to methanol with regard to analyte recovery from the SPE. The volume of acetonitrile in the SPE was also examined. Samples $(5 \mathrm{ml})$ containing analytes at $50 \mathrm{ng} \cdot \mathrm{ml}^{-1}$ were accurately measured and subjected to the "sample preparation" procedure (Section 2.4) described above. Analytes on the Isolute multimode column were eluted with different volumes of acetonitrile $(1,0.5,0.5,0.5,0.5,1$ and $1 \mathrm{ml})$, and were collected and diluted with the same volume of water for LC-MS/MS analysis. The results are shown in Table 3. The cumulative amounts of analytes desorbed from the SPE cartridge increased with eluent volume. Acetonitrile at $2.5 \mathrm{ml}$ was selected as the adequate volume for elution in our experiments.

\subsection{Calibration, Quantitation and Recovery}

Calibration curves for BPA, NP and $n$-NP were obtained from the peak-area ratio (BPA/BPA-d16) versus BPA concentration, (NP/NP-d5) versus NP concentration and ( $n$-NP/n-NP-d4) versus $n$-NP concentration, respec- tively. Calibration curves exhibited satisfactory linear relationships in the range of $0.2-40 \mathrm{ng} \cdot \mathrm{ml}^{-1}$. The correlation coefficients for standard curves in ten trials were in the range of $0.996-1.000,0.993-1.000$ and $0.995-$ 1.000 for BPA, NP and $n$-NP, respectively.

The means and standard deviations (SDs) of the slope and intercept, and the mean of correlation coefficients are shown in Table 4. The mean and SD of background levels of NP in the prepared test solution was $1.58 \pm 0.34$ $(\mathrm{n}=10)$. The LOQ of NP determined by the equation, "LOQ = Average of background $+\mathrm{SD} \times 10$," was 5 $\mathrm{ng} \cdot \mathrm{ml}^{-1}$. With regard to BPA and $\underline{n}-\mathrm{NP}$, contamination from the laboratory atmosphere or/and the materials used during analysis were not observed. The standard solution was added to a blank solution of each sample (IVFM and $\mathrm{SWM}$ ) in order to make $0.5 \mathrm{ng} \cdot \mathrm{ml}^{-1}$, and $\mathrm{S} / \mathrm{N}$ ratio was investigated. In all samples, the $\mathrm{S} / \mathrm{N}$ ratio was above 10 ; the limit of quantitation of BPA and $n$-NP was estimated as $0.5 \mathrm{ng} \cdot \mathrm{ml}^{-1}$.

Recovery, repeatability and reproducibility of analytes were investigated by determining triplicate samples daily for 3 days. The results are shown in Table 5. Recoveries were $96.3 \%-103.2 \%, 90.0 \%-97.2 \%$ and $95.6 \%$ $100.2 \%$, the ranges of repeatability were $1.1 \%-2.2 \%$, $1.1 \%-4.2 \%$ and $1.5 \%-3.8 \%$, and the ranges of inter-day precision were $2.2 \%-5.4 \%, 2.2 \%-9.2 \%$ and $2.1 \%-7.0 \%$ for BPA, NP and $n$-NP, respectively.

\subsection{Measurement of BPA, NP and $n-N P$ in IVFM Samples}

$\mathrm{BPA}, \mathrm{NP}$ and $n$-NP concentrations in commercial samples of IVFM, SWM, HSA and SS were investigated. Sources of BPA, NP and $n$-NP would be present in the

Table 3. Incremental elution efficiencies for BPA, NP and $n$-NP obtained with different volumes of elution solvent (\%).

\begin{tabular}{ccccccccc}
\hline & \multicolumn{7}{c}{ Elution volume of acetonitrile (ml) } \\
\cline { 2 - 8 } Analytes $^{\mathrm{a}}$ & 1.0 & 0.5 & 0.5 & 0.5 & 0.5 & 1.0 & 1.0 \\
\hline BPA & 80.3 & 16.3 & 3.1 & 0 & 0 & 0 & 0 \\
NP & 69.7 & 28.4 & 1.0 & 0.5 & 0.1 & 0.1 & 0 \\
n-NP & 64.2 & 26.8 & 6.1 & 2.1 & 0 & 0.1 & 0 \\
\hline
\end{tabular}

Notes: ${ }^{a} \mathrm{BPA}$, bisphenol A; NP, 4-nonylphenol; $\underline{n}$-NP, 4- $\underline{n}$-nonylphenol.

Table 4. Calibration curves for BPA, NP and n-NP.

\begin{tabular}{|c|c|c|c|c|c|c|}
\hline \multirow{2}{*}{ Analytes $^{\mathrm{a}}$} & Slope & Intercept & \multirow{2}{*}{ Liner Range $\left(\mathrm{ng} \cdot \mathrm{ml}^{-1}\right)$} & \multirow{2}{*}{$\begin{array}{l}\text { Correlation } \\
\text { Coefficient }\end{array}$} & \multirow{2}{*}{$\begin{array}{c}\text { Background }\left(\mathrm{ng} \cdot \mathrm{ml}^{-1}\right) \\
(\text { Average } \pm \mathrm{SD})\end{array}$} & \multirow{2}{*}{$\mathrm{LOQ}\left(\mathrm{ng} \cdot \mathrm{ml}^{-1}\right)$} \\
\hline & (Average $\pm \mathrm{SD}$ ) & (Average \pm SD) & & & & \\
\hline BPA & $1.397 \pm 0.095$ & $0.064 \pm 0.030$ & $0.2-40$ & 0.999 & 0 & $0.5^{\mathrm{b}}$ \\
\hline NP & $1.325 \pm 0.091$ & $0.692 \pm 0.187$ & $0.2-40$ & 0.996 & $1.58 \pm 0.34$ & $5^{\mathrm{c}}$ \\
\hline n-NP & $1.338 \pm 0.034$ & $0.092 \pm 0.064$ & $0.2-40$ & 0.998 & 0 & $0.5^{\mathrm{b}}$ \\
\hline
\end{tabular}

Notes: ${ }^{\mathrm{a}} \mathrm{BPA}$, bisphenol A; NP, 4-nonylphenol; $\underline{n}$-NP, $4-\underline{n}$-nonylphenol. ${ }^{\mathrm{b}} \mathrm{LOQ}$ was caliculated the S/N ratio > 10; ${ }^{\mathrm{c}} \mathrm{LOQ}$ was caliculated from average of background level $+\mathrm{SD} \times 10$. 
Table 5. Recoveries for bisphenol A, 4-nonylphenol and 4-n-nonylphenol using the proposed analytical method.

\begin{tabular}{|c|c|c|c|c|c|c|c|c|c|c|c|c|}
\hline \multirow[b]{2}{*}{ Sample } & \multirow[b]{2}{*}{$\begin{array}{c}\text { Fortification } \\
\left(\mathrm{ng} \cdot \mathrm{ml}^{-1}\right)\end{array}$} & \multicolumn{4}{|c|}{ Bisphenol A } & \multicolumn{3}{|c|}{ 4-Nonylphenol } & \multicolumn{4}{|c|}{ 4- $\underline{n}$-Nonylphenol } \\
\hline & & $\begin{array}{l}\text { Recovery } \\
(\%)\end{array}$ & $\begin{array}{c}\text { Repeatability } \\
(\%)\end{array}$ & $\begin{array}{l}\text { Inter-day } \\
\text { precision } \\
(\%)\end{array}$ & $\begin{array}{l}\text { Original } \\
\left(\mathrm{ng} \cdot \mathrm{ml}^{-1}\right)\end{array}$ & $\begin{array}{c}\text { Found } \\
\left(\mathrm{ng} \cdot \mathrm{ml}^{-1}\right)\end{array}$ & $\begin{array}{c}\text { Recovery } \\
(\%)\end{array}$ & $\begin{array}{c}\text { Repeatability } \\
(\%)\end{array}$ & $\begin{array}{l}\text { Inter-day } \\
\text { precision } \\
(\%)\end{array}$ & $\begin{array}{c}\text { Recovery } \\
(\%)\end{array}$ & $\begin{array}{c}\text { Repeatability } \\
(\%)\end{array}$ & $\begin{array}{c}\text { Inter-day } \\
\text { precision } \\
(\%)\end{array}$ \\
\hline $\begin{array}{l}\text { Media for } \\
\text { incubation } \\
\text { of ova }\end{array}$ & 1 & 97.0 & 1.4 & 3.6 & 0 & 0.97 & 97.0 & 1.8 & 6.2 & 99.2 & 2.1 & 3.4 \\
\hline (A011110) & 25 & 99.2 & 1.1 & 2.5 & 0 & 24.3 & 97.2 & 3.0 & 5.4 & 98.3 & 1.5 & 2.1 \\
\hline $\begin{array}{l}\text { Human surum } \\
\text { albmin }\end{array}$ & 10 & 96.3 & 2.2 & 5.4 & 5.5 & 15.1 & 92.7 & 4.2 & 9.2 & 95.6 & 3.4 & 4.8 \\
\hline (A044120) & 25 & 98.2 & 1.5 & 4.4 & 5.5 & 28.5 & 92.0 & 2.3 & 5.3 & 97.5 & 3.1 & 4.9 \\
\hline $\begin{array}{l}\text { Substitute } \\
\text { serum }\end{array}$ & 1 & 100.0 & 1.8 & 2.2 & 9.0 & 9.9 & 90.0 & 1.1 & 2.2 & 100.2 & 2.9 & 7.0 \\
\hline (A025120) & 25 & 103.2 & 1.3 & 3.6 & 9.0 & 32.6 & 94.5 & 3.2 & 4.6 & 98.2 & 3.8 & 4.9 \\
\hline
\end{tabular}

Table 6. BPA, NP and $\underline{n}$-NP concentrations in various media samples, including media for incubation of ova, sperm washing media, human serum albumin and substitute serum.

\begin{tabular}{|c|c|c|c|c|c|c|c|c|c|c|c|}
\hline \multirow{3}{*}{ No. } & \multirow{3}{*}{ Sample } & \multirow{3}{*}{ Lot I } & \multirow{3}{*}{ Lot II } & \multicolumn{2}{|c|}{ Bisphenol A } & \multicolumn{2}{|c|}{ 4-nonylphenol } & \multicolumn{2}{|c|}{ 4-n-nonylphenol } & \multirow{3}{*}{$\begin{array}{l}\text { Type of } \\
\text { protein } \\
\text { source }\end{array}$} & \multirow{3}{*}{$\begin{array}{l}\text { Concentration of } \\
\text { PS }\left(\mathrm{mg} \cdot \mathrm{mL}^{-1}\right)^{\mathrm{c}}\end{array}$} \\
\hline & & & & Lot I & Lot II & Lot I & Lot II & Lot I & Lot II & & \\
\hline & & & & $\mathrm{ng} \cdot \mathrm{ml}^{-1}$ & $\mathrm{ng} \cdot \mathrm{ml}^{-1}$ & $\mathrm{ng} \cdot \mathrm{ml}^{-1}$ & $\mathrm{ng} \cdot \mathrm{ml}^{-1}$ & $\mathrm{ng} \cdot \mathrm{ml}^{-1}$ & $\mathrm{ng} \cdot \mathrm{ml}^{-1}$ & & \\
\hline 1 & IVFM & A011110 & A011120 & N.D. ${ }^{a}$ & N.D. & N.D. ${ }^{b}$ & N.D. & N.D. ${ }^{a}$ & N.D. & HSA & 5 \\
\hline 2 & IVFM & A012110 & A012120 & N.D. & N.D. & N.D. & N.D. & N.D. & N.D. & HSA & 5 \\
\hline 3 & IVFM & A013110 & A013120 & N.D. & N.D. & 7.3 & N.D. & N.D. & N.D. & HSA & 5 \\
\hline 4 & IVFM & A021110 & A021120 & N.D. & N.D. & N.D. & N.D. & N.D. & N.D. & HSA & 3 \\
\hline 5 & IVFM & A022110 & A022120 & N.D. & N.D. & N.D. & N.D. & N.D. & N.D. & SS & 5 \\
\hline 6 & IVFM & A023110 & A023120 & N.D. & N.D. & N.D. & N.D. & N.D. & N.D. & SS & 5 \\
\hline 7 & IVFM & A031110 & A031120 & N.D. & N.D. & N.D. & N.D. & N.D. & N.D. & SS & 6 \\
\hline 8 & IVFM & A032110 & A032120 & N.D. & N.D. & 14.5 & N.D. & N.D. & N.D. & SS & 6 \\
\hline 9 & IVFM & A033110 & A033120 & N.D. & N.D. & N.D. & 6.3 & N.D. & N.D. & SS & 6 \\
\hline 10 & IVFM & A021210 & A021220 & N.D. & N.D. & N.D. & N.D. & N.D. & N.D. & Not added & - \\
\hline 11 & IVFM & A022210 & A022220 & N.D. & N.D. & N.D. & N.D. & N.D. & N.D. & Not added & - \\
\hline 12 & IVFM & A023210 & A023220 & N.D. & N.D. & N.D. & N.D. & N.D. & N.D. & Not added & - \\
\hline 13 & IVFM & A031210 & A031220 & N.D. & N.D. & N.D. & N.D. & N.D. & N.D. & Not added & - \\
\hline 14 & IVFM & A032210 & A032220 & N.D. & N.D. & N.D. & N.D. & N.D. & N.D. & Not added & _- \\
\hline 15 & IVFM & A033210 & A033220 & N.D. & N.D. & N.D. & N.D. & N.D. & N.D. & Not added & - \\
\hline 16 & SWM & A017110 & A017120 & N.D. & N.D. & N.D. & 5.3 & N.D. & N.D. & HSA & 10 \\
\hline 17 & SWM & A027110 & A027120 & N.D. & N.D. & 16.5 & 8.9 & N.D. & N.D. & HSA & 5 \\
\hline 18 & SWM & A067110 & A067120 & N.D. & N.D. & 21.7 & 14.0 & N.D. & N.D. & HSA & 5 \\
\hline 19 & SWM & A068110 & A068120 & N.D. & N.D. & 5.7 & 6.6 & N.D. & N.D. & HSA & 5 \\
\hline 20 & SWM & A037110 & A037120 & N.D. & N.D. & 7.0 & N.D. & N.D. & N.D. & HSA & 5 \\
\hline 21 & SWM & A018110 & A018120 & N.D. & N.D. & 13.7 & 7.3 & N.D. & N.D. & HSA & 10 \\
\hline 22 & SWM & A019110 & A019120 & N.D. & N.D. & 11.9 & 8.5 & N.D. & N.D. & HSA & 10 \\
\hline 23 & SWM & A038210 & A038220 & N.D. & N.D. & N.D. & N.D. & N.D. & N.D. & Not added & - \\
\hline 24 & SWM & A039210 & A039220 & N.D. & N.D. & N.D. & N.D. & N.D. & N.D. & Not added & - \\
\hline 25 & HSA & A024110 & A024120 & N.D. & N.D. & 77.3 & 54.0 & N.D. & N.D. & HSA & 100 \\
\hline 26 & HSA & A034110 & no data & N.D. & N.D. & 69.5 & no data ${ }^{\mathrm{d}}$ & N.D. & N.D. & HSA & 100 \\
\hline 27 & HSA & A044110 & A044120 & N.D. & N.D. & 11.0 & 5.5 & N.D. & N.D. & HSA & 100 \\
\hline 28 & HSA & A054110 & A054120 & N.D. & N.D. & 164.0 & 85.5 & N.D. & N.D. & HSA & 100 \\
\hline 29 & SS & A025110 & A025120 & N.D. & N.D. & 17.1 & 9.0 & N.D. & N.D. & SS & 50 \\
\hline 30 & SS & A035110 & A035120 & N.D. & N.D. & 19.0 & 11.7 & N.D. & N.D. & SS & 60 \\
\hline
\end{tabular}

Notes: ${ }^{\mathrm{a}}$ not detected (N.D.) $<0.5 \mathrm{ng} \cdot \mathrm{ml}^{-1}$, ${ }^{\mathrm{b}}$ Not detected (N.D.) $<5 \mathrm{ng} \cdot \mathrm{ml}^{-1}$, ${ }^{\mathrm{c}} \mathrm{Sum}$ of HSA and globulins, ${ }^{\mathrm{d}}$ Not be available. 
materials storing the media and PS, and in the manufacturing process. Therefore, two lots were examined for each sample. The results are shown in Table 6. The concentrations of BPA and $n$-NP in all samples were below the LOQs. NP was detected in 3 of 30 samples of IVFM and 12 of 18 SWM in the range of $6.3-14.5$ and 5.3 $21.7 \mathrm{ng} \cdot \mathrm{ml}^{-1}$, respectively. These samples were added HSA or SS as PS at $5-10 \mathrm{mg} \cdot \mathrm{ml}^{-1}$. But NP was not detected from all samples of IVFM and SWM lacking PS. High levels of NP were detected in all 7 HSA samples and 4 SS samples in the range of $5.5-164.0$ and 9.0 $19.0 \mathrm{ng} \cdot \mathrm{ml}^{-1}$, respectively. These results suggest that the NP detected in the media (IVFM and SWM) was derived from PS (HSA and SS). IVFM and SWM would generally be with PS added at a concentration of $5 \%-10 \%$, and NP would therefore be present in IVFM and SWM, and ova may be exposed to NP before implantation into the patient's uterus.

With regard to the pharmacokinetic behavior of NP, few studies have been reported. Müller et al. [17] reported that NP was excreted in urine as NP or conjugated NP (e.g., glucuronide). Zalko et al. [18] also reported that, in rats, a major percentage of orally administered NP was excreted in urine in the form of free, glucuronidated or sulfated oxidative metabolites. The concentrations of NP shown in Table 6 correspond to free NP. We then investigated the concentrations of NP conjugated with glucuronic acid in sample A024120 (No.25 Lot II) and A054120 (No.28 Lot II) (see Table 6) due to the presence of human plasma (HSA and SS). The concentrations of NP (combined free and conjugated NP) in A024120 or A054120 were 55.2 and $86.4 \mathrm{ng} \cdot \mathrm{ml}^{-1}$, respectively. The concentrations of free NP in A024120 or A054120 were 54.0 and $85.5 \mathrm{ng} \cdot \mathrm{ml}^{-1}$, respectively (Table 6). These concentrations suggest that NP conjugated with glucuronic acid was presented in HSA at trace levels $\left(\sim 1 \mathrm{ng} \cdot \mathrm{ml}^{-1}\right)$. Inoue et al. [19] also been reported that very low concentrations of free NP were presented in healthy human plasma. We [20] also reported that di (2ethylhexyl) phthalate and its hydrolyzed product mono (2-ethylhexyl) phthalate were highly detected in commercially available HSA, and the sources of these contaminants would universally exist in manufacturing process or ingredients of HSA. These references and our results guess that the detected NP in the HSA and SS samples are not the result of blood materials, and are probably due to contaminating NP from the plastic material used for collection or preparation of the blood sample, or the manufacturing process.

\section{CONCLUSIONS}

A simple method using LC-MS/MS for the simultaneous determination of BPA, NP and $n$-NP in IVF media was investigated. The LOQs were $0.5 \mathrm{ng} \cdot \mathrm{ml}^{-1}$ for BPA, 5 $\mathrm{ng} \cdot \mathrm{ml}^{-1}$ for NP and $0.5 \mathrm{ng} \cdot \mathrm{ml}^{-1}$ for $n$-NP. The recoveries for all compounds in the fortified samples were above $90 \%$. This method was applied to 59 IVF media samples commercially available in Japan, and NP was detected in 26 samples in the range of $5.3-164.0 \mathrm{ng} \cdot \mathrm{ml}^{-1}$. A survey of chemical contaminants in IVFM and SWM is therefore important for improving the quality of IVF treatment.

\section{ACKNOWLEDGEMENTS}

This work was supported by grants from the Ministry of Health and Welfare of Japan. We would also like to thank Prof. Norihiro Sugino, Dr. Ryo Maekawa and Dr. Masahiro Sumie (Yamaguchi University Graduate School of Medicine) for their valuable advice and helpful discussions with regard to this study.

\section{REFERENCES}

[1] Yoshida, T., Horie, M., Hoshino, Y. and Nakazawa, H. (2001) Determination of bisphenol A in canned vegetables and fruit by high performance liquid chromatography. Food Additives and Contaminants, 18, 69-75. doi: $10.1080 / 026520301446412$

[2] Kang, J.-H. and Kondo, F. (2002) Bisphenol a migration from cans containing coffee and caffeine. Food Additives and Contaminants, 19, 886-890. doi:10.1080/02652030210147278

[3] Nerín, C., Fernández, C., Domeňo, C. and Salafranca, J. (2003) Determination of potential migrants in polycarbonate containers used for microwave ovens by highperformance liquid chromatography with ultraviolet and flurosence detection. Journal of Agricultural and Food Chemistry, 51, 5647-5653. doi:10.1021/jf034330p

[4] Lopez-Cervantes, J. and Paseiro-Losada, P. (2003) Determination of bisphenol $\mathrm{A}$ in, and its migration from, PVC stretch film used for food packaging. Food Additives and Contaminants, 20, 596-606. doi:10.1080/0265203031000109495

[5] Emilia, F., Elisa, S., Sauro, V., Guillermina, F., Jordi, M. and Gianni, S. (2011) Simltaneous determination of bisphenol A, octylphenol, and nonylphenol by pressurized liquid extraction and liquid chromatography-tandem mass spectrometry in powdered milk and infant formulas. Food Chemistry, 126, 360-367.

doi:10.1016/j.foodchem.2010.10.098

[6] Marina, D.C., Carlo, S., Camilla, L. and Emanuele, M. (2010) Development of a fast liquid chromatography-tandem mass spectrometry method for the determination of endocrinedisrupting compounds in waters. Analytical and Bioanalytical Chemistry, 398, 1025-1034. doi:10.1007/s00216-010-3985-0

[7] Loyo-Rosales, J.E., Rosales-Rivera, G.C., Lynch, A.M., Rice, C.P. and Torrents, A. (2004) Migration of nonylphenol from plastic containers to water and a milk surrogate. Journal of Agricultural and Food Chemistry, 52, 2016 2020. doi:10.1021/jf0345696

[8] Alexander, H.C., Dill, D.C., Smith, L.W., Guiney, P.D. 
and Dorn, P. (1988) Bisphenol A: Acute aquatic toxicity. Environmental Toxicology \& Chemistry, 7, 19-26. doi:10.1002/etc.5620070104

[9] Yokota, H., Seki, M., Maeda, M., Oshima, Y., Tadokoro, H., Honjo, T. and Kobayashi, K. (2001) Life-cycle toxicity of 4-nonylphenol to medaka (Oryzias latipes). Environmental Toxicology \& Chemistry, 20, 2552-2560.

[10] Soares, A., Guieysse, B., Jefferson, B., Cartmell, E. and Lester, J.N. (2008) Nonylphenol in the environment: A critical review on occurrence, fate, toxicity and treatment in wastewaters. Environment International, 34, 10331049. doi:10.1016/j.envint.2008.01.004

[11] Uchiyama, T., Makino, M., Saito, H., Katase, T. and Fujimoto, Y. (2008) Syntheses and estrogenic activity of 4nonylphenol isomers. Chemosphere, 73, 60-65. doi:10.1016/i.chemosphere.2006.12.103

[12] Kim, H.S., Shin, J.-H., Moon, H.-J., Kang, I.H., Kim, T.S., Kim, I.Y., Seok, J.-H., Pyo, M.-Y. and Han, S.Y. (2002) Comparative estrogenic effects of p-nonylphenol by 3day uterotrophic assay and female pubertal onset assay. Reproductive Toxicology, 16, 259-268. doi:10.1016/S0890-6238(02)00028-X

[13] Hemmer, M.J., Hemmer, B.L., Bowman, C.J., Kroll, K.J., Folmar, L.C., Marcovich, D., Hoglund, M.D. and Denslow, N.D. (2001) Effects of p-nonylphenol, methoxychlor, and endosulfan on vitellogenin induction and expression in sheepshead minnow (Cyprinodon variegatus). Environmental Toxicology \& Chemistry, 20, 336-343.

[14] Hassold, T. and Hunt, P. (2001) To ERR (meiotically) is human: The genesis of human aneuploidy. Nature Reviews
Genetics, 2, 280-291. doi:10.1038/35066065

[15] Wang, J. and Sauer, M.V. (2006) In vitro fertilization (IVF): A review of 3 decades of clinical innovation and technological advancement. Therapeutics and Clinical Risk Management, 2, 355-364. doi:10.2147/tcrm.2006.2.4.355

[16] Horie, M., Kobayashi, H., Ishii, R., Saito, K., Nakazawa, H. and Makino, T. (2007) Determination of Nonylphenol and Octylphenol in Fish and Shellfish by High-Peformance Liquid Chromatography/Electrospray Mass Spectrometry. Bunseki kagaku, 56, 1037-1043. doi:10.2116/bunsekikagaku.56.1037

[17] Müller, S., Schmid, P. and Schlatter, C. (1998) Pharmacokinetic behavior of 4-nonylphenol in humans. Environmental Toxicology and Pharmacology, 5, 257-265. doi:10.1016/S1382-6689(98)00009-X

[18] Zalko, D., Costagliola, R., Dorio, C., Rathahao, E. and Cravedi, J.-P. (2003) In vivo metabolic fate of the xeno-estrogen 4-n-nonylphenol in wistar rats. Drug Metabolism and Disposition, 31, 168-178. doi:10.1124/dmd.31.2.168

[19] Inoue, K., Yoshimura, Y., Makino, T. and Nakazawa, H. (2000) Determination of 4-nonylphenol and 4-octylphenol in human blood samples by high-performane liquid chromatography with multi-electrode electrochemical coulometric-array detection. Analyst, 125, 1959-1961. doi:10.1039/b006597h

[20] Takatori, S., Akutsu, K., Kondo F., Ishii, R., Nakazawa, H. and Makino, T. (2012) Di (2-ethylhexyl) phthalate and mono (2-ethylhexyl) phthalate in media for in vitro fertilization. Chemosphere, 86, 454-459. doi:10.1016/j.chemosphere.2011.09.043 